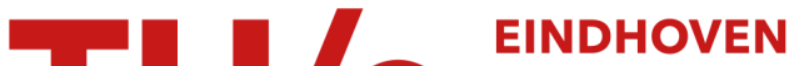

\section{Performance degradation of integrated optical modulators due to electrical crosstalk}

\section{Citation for published version (APA):}

Yao, W., Gilardi, G., Smit, M. K., \& Wale, M. J. (2016). Performance degradation of integrated optical modulators due to electrical crosstalk. Journal of Lightwave Technology, 34(13), 3080 - 3086.

https://doi.org/10.1109/JLT.2016.2572222

DOI:

10.1109/JLT.2016.2572222

Document status and date:

Published: 01/07/2016

\section{Document Version:}

Publisher's PDF, also known as Version of Record (includes final page, issue and volume numbers)

\section{Please check the document version of this publication:}

- A submitted manuscript is the version of the article upon submission and before peer-review. There can be important differences between the submitted version and the official published version of record. People interested in the research are advised to contact the author for the final version of the publication, or visit the $\mathrm{DOI}$ to the publisher's website.

- The final author version and the galley proof are versions of the publication after peer review.

- The final published version features the final layout of the paper including the volume, issue and page numbers.

Link to publication

\section{General rights}

Copyright and moral rights for the publications made accessible in the public portal are retained by the authors and/or other copyright owners and it is a condition of accessing publications that users recognise and abide by the legal requirements associated with these rights.

- Users may download and print one copy of any publication from the public portal for the purpose of private study or research.

- You may not further distribute the material or use it for any profit-making activity or commercial gain

- You may freely distribute the URL identifying the publication in the public portal.

If the publication is distributed under the terms of Article 25fa of the Dutch Copyright Act, indicated by the "Taverne" license above, please follow below link for the End User Agreement:

www.tue.nl/taverne

Take down policy

If you believe that this document breaches copyright please contact us at:

openaccess@tue.nl

providing details and we will investigate your claim. 


\title{
Performance Degradation of Integrated Optical Modulators Due to Electrical Crosstalk
}

\author{
Weiming Yao, Student Member, IEEE, Giovanni Gilardi, Meint K. Smit, Fellow, IEEE, \\ and Michael J. Wale, Member, IEEE, Member, OSA
}

\begin{abstract}
In this paper, we investigate electrical crosstalk in integrated Mach-Zehnder modulator arrays based on n-doped InP substrate and show that it can be the cause for transmitter performance degradations. In particular, a common ground return path between adjacent modulators can cause high coupling noise up to $-20 \mathrm{~dB}$ which leads to system power penalties of more than $10 \mathrm{~dB}$ at $10 \mathrm{~Gb} / \mathrm{s}$ OOK modulation. Furthermore, we demonstrate that electrical crosstalk is significantly reduced in the absence of the shared ground and that it varies with modulator separation distance. Experimental results are shown that indicate a crosstalk tolerance of $-40 \mathrm{~dB}$ for $1 \mathrm{~dB}$ power penalty at $10 \mathrm{~Gb} / \mathrm{s}$.
\end{abstract}

Index Terms-Integrated modulators, photonic integrated circuits.

\section{INTRODUCTION}

$\mathbf{P}$ HOTONIC integrated circuits (PICs) have gained increased popularity in high-capacity optical transmitter and receiver applications. High scalability, elevated functionality, low power consumption and low cost are all potential advantages that lead to a big research effort into InP-based integration technologies which are capable of monolithically integrating active and passive components on the same chip. Early examples such as $100 \mathrm{~Gb} / \mathrm{s}$ WDM transmitters [1] and, more recently, 1 Tbps transmitters [2] show that high integration density and scalability can be successfully applied to PICs. Further increase in parallel channel count and component density will soon lead to an even higher transmission capacity per chip. Meanwhile, recent progress in generic foundry development for PICs was able to reduce the entry cost to photonic integration technology and offer foundry services to a wide user base [3], so that a whole range of low-cost multi-channel WDM transmitter circuits have been realized [4]-[7]. It is undeniable that photonic chips will become progressively more complex in the future and that the integration technology will keep on maturing towards higher component density and smaller footprint. However, several challenges associated with this kind of scaling need to be addressed first. Proximity effects between components in form

Manuscript received December 14, 2015; revised February 29, 2016 and May 14, 2016; accepted May 17, 2016. Date of publication May 23, 2016; date of current version June 22, 2016. This work was supported by the Dutch STW ELPHI project, the STW foundation, and the Smart Photonics foundry.

W. Yao, G. Gilardi, and M. K. are with the Department of Electrical Engineering, Technical University of Eindhoven, Eindhoven 5600 MB, the Netherlands (e-mail: w.yao@tue.nl; g.gilardi@tue.nl; m.k.smit@ tue.nl).

M. J. Wale is with Oclaro Technology, Ltd., Towcester NN12 8EQ, U.K. (e-mail: mike.wale@oclaro.com).

Color versions of one or more of the figures in this paper are available online at http://ieeexplore.ieee.org.

Digital Object Identifier 10.1109/JLT.2016.2572222 of thermal, electrical and optical crosstalk emerge and start to limit the chip performance. In this paper, we focus on electrical crosstalk in PICs, in particular inside high-speed modulator arrays. Previous work from [8], [9] on a packaged DFB laser array with electro-absorption modulators has indicated that transmission power penalties can exist due to electrical crosstalk from the assembly and the PIC. They reported crosstalk simulations of RF traces in the package but did not show any measurement results for the assembly and PIC. Crosstalk induced power penalty in a directly modulated laser diode and receiver array has been observed in [10] and it was recommended to avoid a common ground plane between channels. Recent work by us has confirmed that electrical coupling in case of Mach-Zehnder modulators (MZM) also degrades its transmission performance, leading to significant power penalties, when they are operated simultaneously [11]. Measurements between coupled RF lines on the same PIC verified that high electrical crosstalk can be introduced due to a common, imperfect ground plane and a simulation approach has been presented that is able to estimate the electrical coupling [12]. In absence of this shared ground connection, overall crosstalk is lower and therefore less degradation is observed in simultaneously operated modulators [13]. The coupling depends on the electrode separation distance in this case and measurements in [12] on coupled RF lines support this observation. However, no experimental results on the coupling between modulator phase-shifters were presented, which is the focus of this paper. We study the crosstalk behavior of four different modulator phase-shifter types and its dependence on separation distance, present eye diagram and bit-error-rate (BER) measurement results for both cases with and without the influence of a shared ground connection and show crosstalk tolerance results for different transmission bit rates. The four modulator types and their fabrication are first described. After that, electrical crosstalk measurements are presented and finally measurements on performance degradation are discussed.

\section{Modulator Structure}

The devices used in this work were all fabricated in the COBRA generic foundry process which provides a common platform for integrating active and passive components. It has been successfully used for a variety of applications up till now so broad applicability of the obtained results from this study is ensured. The platform is based on an n-doped InP substrate with backside metalization and epitaxially grown layers that form a p-i-n-junction for vertical wave-guiding. Fig. 1 shows the cross-section of the RF line and modulator phase-shifter in 


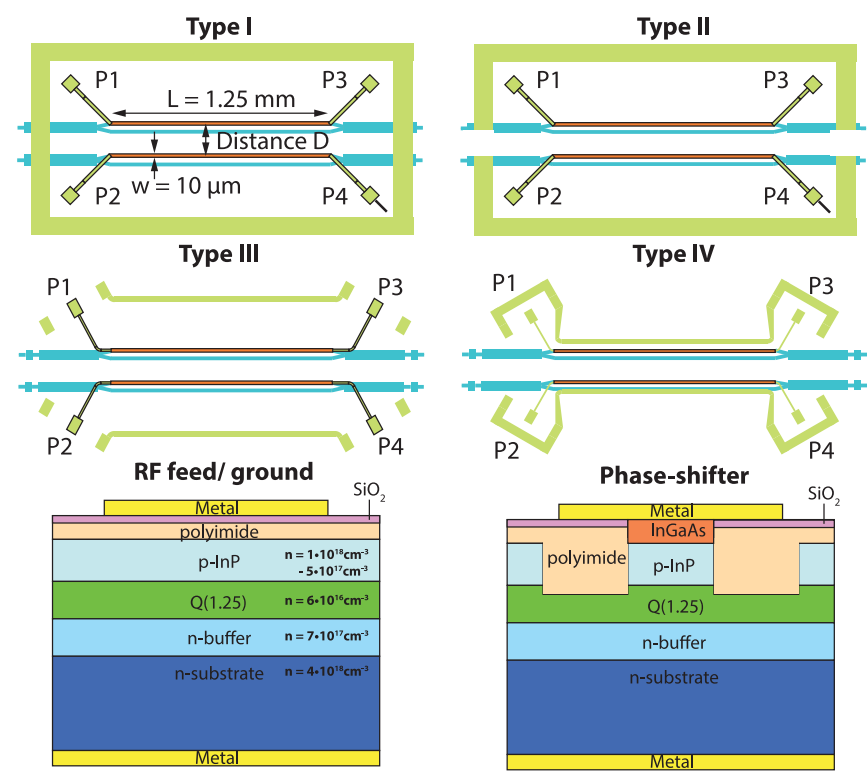

Fig. 1. Schematic layout (top) of four tested types of MZM pairs. Crosssection (bottom) of RF feed line and modulator phase-shifter in generic integration process.

this platform. The RF line is formed by evaporating metal on top of a $500 \mathrm{~nm}$ thick passivation layer consisting of polyimide and silicon dioxide. The phase-shifter consists of a passive optical ridge waveguide with bulk quaternary core material (Q-1.25) that is in contact with the top metal through a p-doped InP and a highly doped InGaAs layer to reduce contact resistance. The thickness and doping profile of the p-InP affect both the optical and electrical losses, which are in a trade-off. Highly doped and thinner p-layer will reduce RF attenuation due to a smaller series resistance but increase free carrier absorption of the optical wave whereas low doping leads to less optical loss at the expense of higher RF attenuation. A good compromise with $1.3 \mu \mathrm{m}$ thickness and a gradual doping concentration from $1 \times 10^{18} \mathrm{~cm}^{-3}$ to $5 \times 10^{17} \mathrm{~cm}^{-3}$ was chosen for the generic platform.

The test structures are formed out of pairs of reverse biased single-drive traveling-wave MZM, that utilize the bulk electrooptic effect. Four different types have been designed and realized through several fabrication runs and are schematically shown in Fig. 1. They all have in common that the data signal enters the modulator from one side through a coplanar RF pad and co-propagates with the optical signal, so that the electrooptic interaction takes place along the whole electrode length, overcoming the lumped RC bandwidth limitation. During this propagation, electrical coupling of the data signal can occur to the neighboring modulator's electrode and affect the local modulation there. The coupling characteristics and strength depends on the separation distance and signal electrode width. Wider electrodes exhibit higher coupling but it has been shown that its influence is much smaller compared to that of the separation distance [12]. Here we focus on the latter effect which can be experimentally obtained from the test structures. Furthermore, the

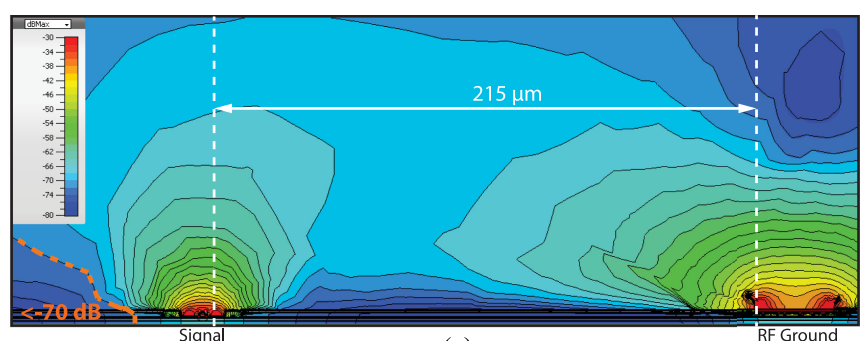

(a)

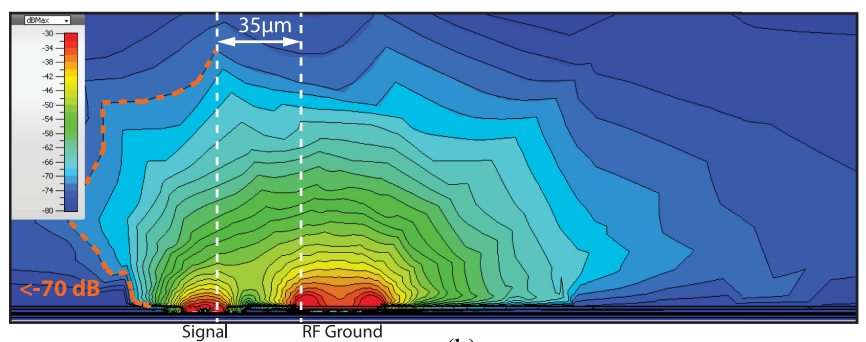

(b)

Fig. 2. Simulated microwave mode profile (E-field) at $10 \mathrm{GHz}$ for wide gap (type I-III) and narrow gap modulator (type IV).

coupling introduces transmission power penalties in the modulators which can be related to the electrical crosstalk level.

Type I modulators have been previously reported in [12] and consist of two single-drive MZMs where the return current flows through a common ground ring that is shared by both modulators. It has been found that this shared connection introduces ground bounce noise, because the return current of each modulator can flow through the other modulators's ground path and get picked up as noise. In the type II structure, the ring has been disconnected at the middle point between both modulators, so that ground bounce is eliminated and overall crosstalk is significantly reduced [13]. Type III and type IV modulators also utilize isolated ground returns but have narrower ground electrodes, as simulations have predicted better RF performance in that case. The former has a large gap between signal metal and ground metal so that its microwave propagation mode is concentrated in the depletion region (Q-1.25) and underneath the ground metal of the phase-shifter, resembling that of a microstrip line. For type IV modulators, the propagation occurs through a hybrid microstrip-stripline mode, as the signal and ground metal are very close to each other. Although the majority of the field is still concentrated in the depletion area under the signal electrode, due to the proximity of the ground metal to the signal metal, a stripline mode exists between the two and contributes to the microwave propagation. This is illustrated in Fig. 2 where the simulated microwave mode profile is shown for the narrow gap and wide gap electrodes respectively.

For each modulator type, various pairs have been fabricated with changing separation distances and a constant interaction length of $\mathrm{L}=1.25 \mathrm{~mm}$, yielding a $V_{\pi}$ voltage of around 10 $\mathrm{V}$ in bulk InGaAsP. Longer electrode lengths exhibit more electro-optic interaction and therefore lower $V_{\pi}$ values but at the expense of smaller modulation bandwidth due to a higher total RF attenuation. Consequently, the length has been chosen as a 


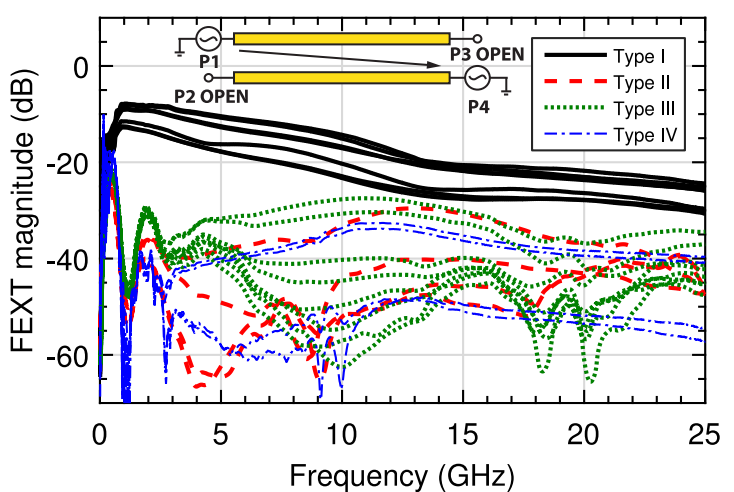

(a)

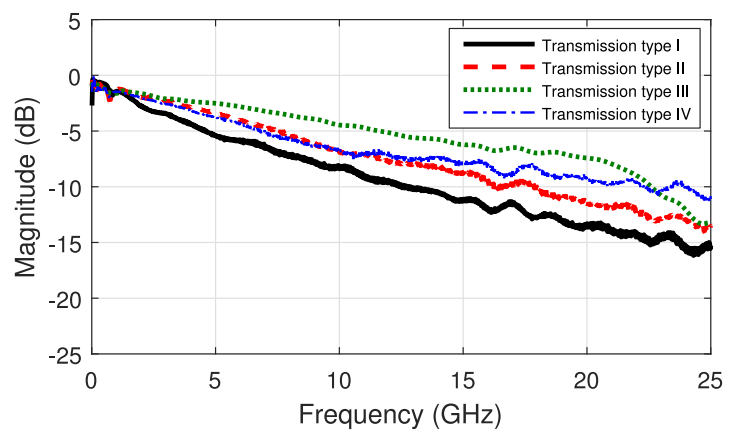

(c)

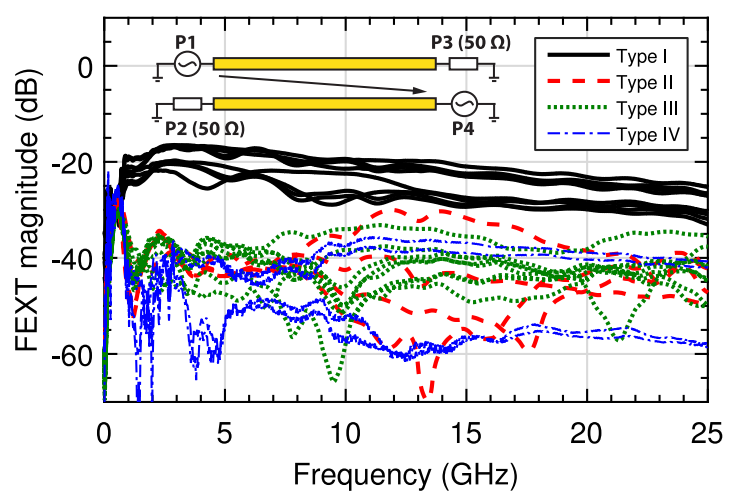

(b)

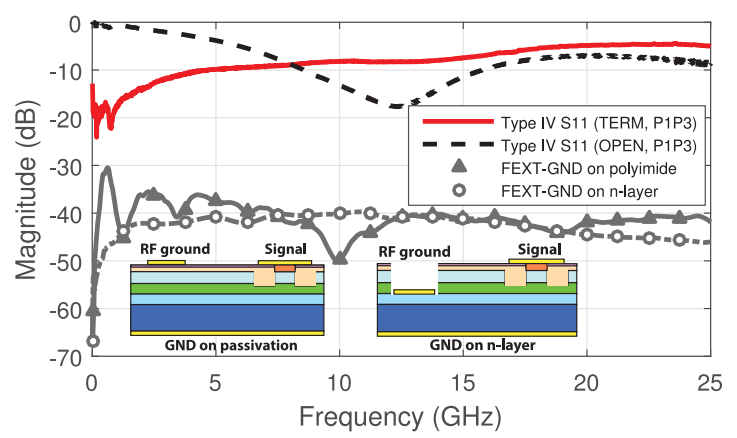

(d)

Fig. 3. Frequency dependent crosstalk characteristics of modulator pairs of different types for (a) open and (b) terminated configurations. Different curves of the same type are for various separation distances. Except for type II devices, two different samples have been measured. (c) Measured electrical S21 parameter of four types of modulator electrodes. (d) Far-end crosstalk (FEXT) for the case when ground lies on passivation or n-doped InP; S11 response of type IV modulators for terminated and open cases.

TABLE I

Device Geometry of Test Structures

\begin{tabular}{lccc}
\hline \hline Device & Separation D $(\mu \mathrm{m})$ & Signal width $(\mu \mathrm{m})$ & Samples \\
\hline Type I & $30,80,180,280$ & 10 & 2 \\
Type II & $30,80,180,280$ & 10 & 1 \\
Type III & $50,90,140,190$ & 10 & 2 \\
Type IV & 50,90 & 10 & 2 \\
\hline \hline
\end{tabular}

compromise between the two. The corresponding electrical frequency responses of the four electrode types are shown in Fig. 3(c). The $-6 \mathrm{~dB}$ bandwidth is above $7 \mathrm{GHz}$ for all four electrode types making them suitable for $10 \mathrm{~Gb} / \mathrm{s}$ operation. Limitations to the modulator bandwidth in general arise from $\mathrm{RF}$ attenuation and impedance mismatch to the driver. The former can be reduced by further shortening the electrode length and using more efficient electro-optic materials such as multi quantum-wells or by utilizing a semi-insulating substrate. The latter can be reduced by optimizing the electrode design towards a $50 \Omega$ impedance value which turns out to be difficult to achieve in practice for phase-shifters based on n-doped substrate [14]. The speed limitations of this generic integration platform lie around $10 \mathrm{~Gb} / \mathrm{s}$ operation but they are well suited for studying the crosstalk behavior between modulators. Table I contains the number of measured samples for each type and their respective separation distances.

\section{ELECTRICAL CROSSTALK}

For characterizing the electrical crosstalk between the pairs of MZMs, a two-port vector network analyzer is used in combination with direct probing of the device under test and standard short-open-load-thru on-wafer calibration, so that no additional fixture effects are introduced into the results. The measurement is performed without DC bias from port 1 to port 4 as indicated in Fig. 1 whereas port 2 and port 3 can be either left open or terminated with $50 \Omega$. In the former case, the propagating RF signal will see an open circuit at the end of the electrode and undergo reflection, so that it travels back to the source. In the latter case, most of the signal will be dissipated in the termination load and only a part will be reflected due to impedance mismatch of the electrode's characteristic impedance with the load resistance. Fig. 3(d) shows the S11 reflection for both cases measured on type IV devices to illustrate this point. In a real world scenario both modulators would be terminated into their respective characteristic impedances, resembling more the second case. The measured characteristics from port 1 to port 4 represent the farend crosstalk noise in the modulator pair which travels alongside the optical signal, affecting its modulation. Because of the electrical symmetry, the crosstalk from port 2 to port 3 is identical and omitted in the following analysis.

Fig. 3(a) and (b) show the frequency dependent crosstalk of the four types of test structures for both the open and terminated cases and all available separation distances. Curves from the same modulator type with lower crosstalk correspond to larger 
separation distances but the exact value has not been specified for the sake of better visibility. There is a significant gap in the crosstalk level of around $20 \mathrm{~dB}$ between type I and the other types of modulators which can be attributed to the common ground connection that both MZMs of type 1 share. This difference in crosstalk decreases at higher frequencies but is still clearly visible. For type II, III and IV devices, the crosstalk level and frequency dependence varies with separation distance and its shape depends on many parameters such as RF bend, probing pad and phase-shifter geometry, so that a simple interpretation of the exact curve and its resonance peaks is not straight forward. However, certain common features can be observed among them. At low frequencies, resonance peaks are visible at $0.5 \mathrm{GHz}$ and $2.5 \mathrm{GHz}$ for type II, III and IV modulators and the crosstalk level takes similar values. This originates from capacitive injection of noise to the substrate through the ground return electrodes. The capacitance is located in the polyimide layer between the top ground metal and the first p-InP layer below it, as can be taken from the inset in Fig. 3(d). Additional measurement results in the same figure on test structures where the ground return electrode lies directly on the n-buffer layer, so that no such capacitance can build up, do not show those resonance peaks. For type I structures, those resonances are masked by ground crosstalk noise which is at a much higher level. At higher frequencies, the measured crosstalk values show strong dependence on separation distance and common features between different modulator types are not easily identifiable anymore.

Within one type of modulators, the crosstalk level can vary for different separation distances. To have a more suitable representation of this effect, the average crosstalk has been calculated by taking the arithmetic mean value from 0 to $25 \mathrm{GHz}$, and plotted in Fig. 4(a) and (b) for the open and terminated cases respectively. Logarithmic fitting has been applied to the data, assuming an inverse square decrease of coupling with distance. It now becomes more evident that crosstalk in type I devices is about $20 \mathrm{~dB}$ higher than in type II to IV devices. This can be observed in both the open and terminated cases. The absolute value does not decrease below $-30 \mathrm{~dB}$ within a range of $300 \mu \mathrm{m}$ for the separation distance. In absence of a shared ground return path, coupling for the type II to IV devices is between $-40 \mathrm{~dB}$ to $-50 \mathrm{~dB}$ for separation distances exceeding $50 \mu \mathrm{m}$. In general, the crosstalk levels in the open case are higher than in the terminated case for separation values less than $100 \mu \mathrm{m}$ and the opposite is true for separation distances larger than $100 \mu \mathrm{m}$. The crosstalk dependence in the open case shows also more variation with separation distance, indicating a radiative mechanism for the coupling. The electrode acts as an antenna where the forward and reflected signals radiate and couple to the next modulator. For the terminated case a return current can exist in the ground return path, which injects noise into the substrate through the passivation capacitance, that gets picked up by the neighboring modulator. A radiative mechanism is responsible for crosstalk in the open case and substrate coupling is dominant in the terminated case.

The level of average crosstalk reduces with increasing separation distance. This observation is strongest in type IV

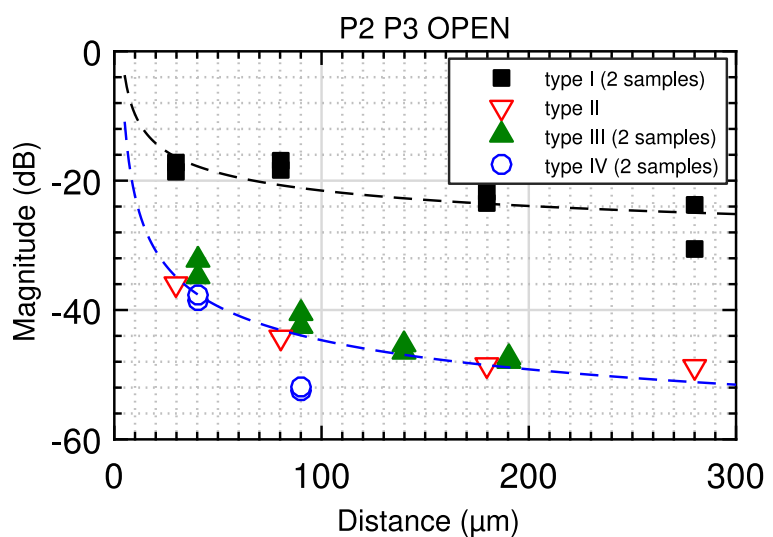

(a)

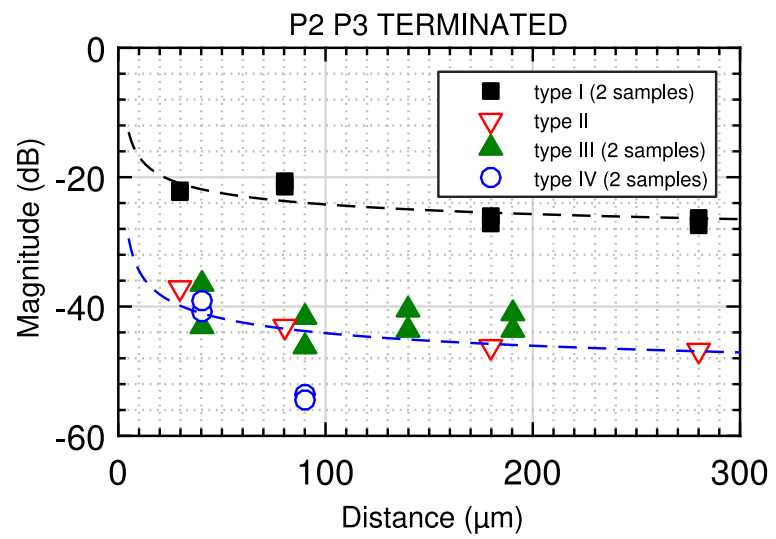

(b)

Fig. 4. Average crosstalk until $25 \mathrm{GHz}$ of the four modulator types depending on separation distance for (a) open and (b) terminated configurations. Except for type II devices, two different samples have been measured.

modulators compared to the other types mainly because the microwave field is less extended into the lateral dimension here, which can be seen in Fig. 2. The smaller gap between signal and ground electrode leads to a more confined propagation mode and less field extends to the neighboring modulator. This can be clearly observed on the $-70 \mathrm{~dB}$ electric field contour line that extends further into the left in case of type I to III modulators, resulting in higher crosstalk. This result suggests that modulators with narrow gap RF electrodes such as coplanar or striplines are better suited for high density integration than modulators with wide gap microstrip electrodes.

The electrical crosstalk results for the four types of modulators show that ground bounce noise leads to significantly higher coupling. In its absence, crosstalk is lower and decreases with separation distance, which is a direct figure of merit for modulator integration density on this foundry platform. If microstrip or stripline transmission lines are used as modulator electrodes, a minimum separation of at least $50 \mu \mathrm{m}$ needs to be retained in order to keep the crosstalk level below $-40 \mathrm{~dB}$.

\section{Performance Degradation}

To assess the influence of electrical crosstalk on the transmission performance, the same test structures as before can be used. 


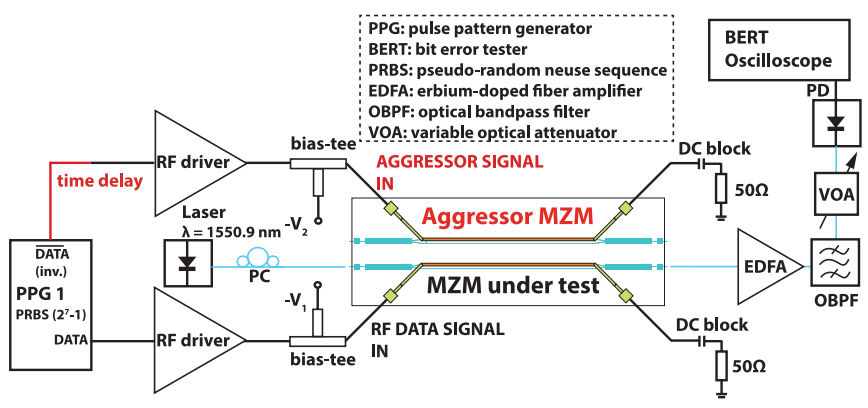

Fig. 5. Experimental setup for measuring BER of modulator pairs. The uncorrelated inverted data signal is used for the aggressor signal after verifying this technique using a second pulse pattern generator in a control measurement.

The performance of one modulator is measured and compared to the case when the neighboring modulator, the aggressor, is switched on. As crosstalk noise from the aggressor modulator travels along the victim modulator's electrode, it affects the change of refractive index and turns into noise in the optical output signal. The measurement setup is shown in Fig. 5. Both modulators are biased at their quadrature point and a PRBS sequence of $2^{7}-1$ which is amplified to $5 V_{\mathrm{pp}}$ is used for the drive signal and the delayed inverted sequence as the aggressor signal. A coaxial cable delay of around 20 bit periods at $10 \mathrm{~Gb} / \mathrm{s}$ was used. For the measurements we had only one PPG available and we generated the second signal by delaying the first signal sufficiently to get decorrelated signals. We validated this approach using a second PPG which we could only use for a short time and the results are consistent with those generated by the single source. This confirms that our methodology of using a single PPG for both the drive and aggressor signal is valid. The two modulator electrodes are terminated with DC blocks and $50 \Omega$ loads respectively. Eye diagrams are taken at $0 \mathrm{dBm}$ optical power after amplification and bandpass filtering (BW $<1 \mathrm{~nm}$ ).

Fig. 6(a) shows the experimental results for the type I structure. The modulation eye diagram is clear and open but when the second modulator is switched on, noise is added to it and the eye opening is reduced. This effect is more severe at higher modulation speed, which can also be seen in the BER measurements. The additional power penalty introduced by crosstalk to the back-to-back transmission increases with modulation speed. At $10 \mathrm{~Gb} / \mathrm{s}$ the modulator approaches its bandwidth limitation which explains the emergence of an error floor in the BER measurements. In case of the type II modulators however, almost no eye diagram degradation is observed due to crosstalk from the second modulator, as shown in Fig. 6(b). Here, the overall coupling is much lower because of the absence of the shared ground return path. Additional power penalties to the transmission as shown in the BER measurement are lower with respect to type I modulators. This difference is summarized in Fig. 7 where the crosstalk induced power penalty is plotted for various modulator types and bit rates. Clearly, the type I modulators perform worst and the other modulator types that do not suffer from ground bounce noise are subject to less crosstalk induced power penalty. Type IV modulators show the least power penalty due to the low coupling they exhibit. Because of a technology issue affecting

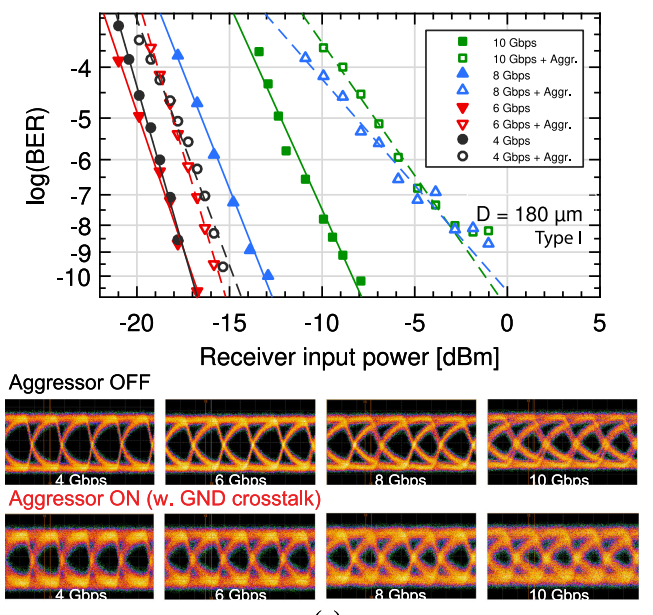

(a)

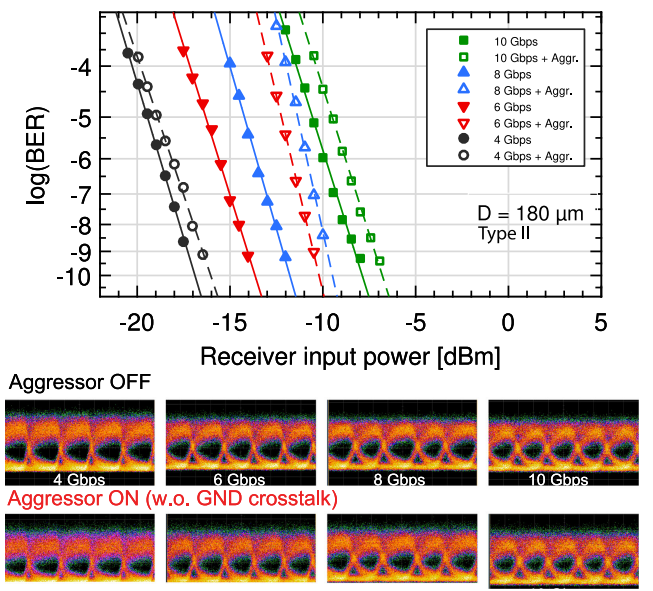

(b)

Fig. 6. BER measurements and eye-diagrams with and without aggressor modulator switched on for (a) type I modulators with ground noise and (b) type II modulators without ground noise.

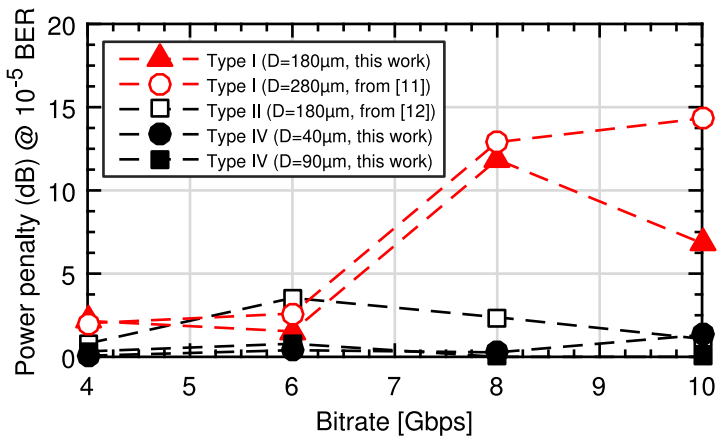

Fig. 7. Crosstalk power penalty introduced to back-to-back transmission with and without the presence of ground noise.

the electrical contacting in type III modulators, performance degradation measurements could not be performed on those.

The experimental results show conclusively that less electrical crosstalk is present when ground noise is eliminated. To estimate the crosstalk tolerance of modulators, we relate the average crosstalk to the corresponding power penalty values for different bit rates. This is shown in Fig. 8. It can be observed, that at low crosstalk values almost no power penalty exists 


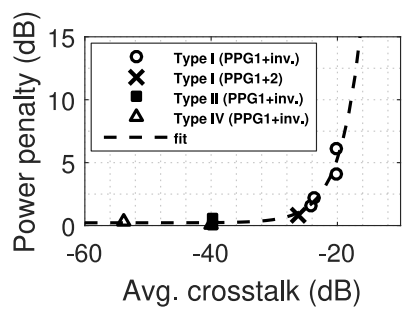

(a)

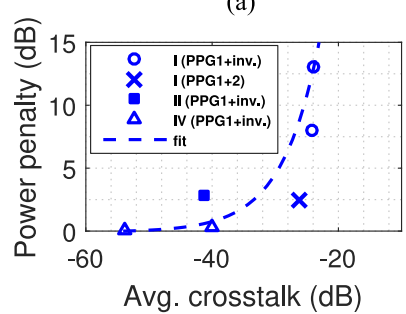

(c)

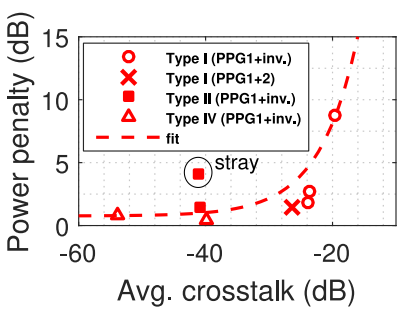

(b)

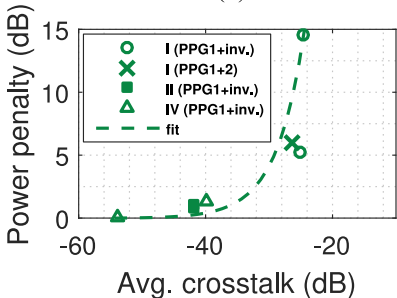

(d)
Fig. 8. Relation between average crosstalk level and additional power penalty at $10^{-5}$ BER for different bit rates obtained from experiment.

but as the coupling exceeds a certain threshold, the penalty increases rapidly. This behavior has been observed before for interferometric optical crosstalk in WDM channels, where the penalty follows an exponential increase with crosstalk, which is typical for impairments due to noise [15], [16]. The $1 \mathrm{~dB}$ penalty threshold is at a crosstalk level of $-40 \mathrm{~dB}$ for 6,8 and $10 \mathrm{~Gb} / \mathrm{s}$ and more relaxed at $-30 \mathrm{~dB}$ for $4 \mathrm{~Gb} / \mathrm{s}$ modulation speed. This suggests that crosstalk impairment becomes more limiting at higher modulation speeds beyond $10 \mathrm{~Gb} / \mathrm{s}$. The measured data from two separate PPGs fits well into the data set generated by one single PPG, ensuring the validity of the latter approach. The estimated crosstalk tolerance together with the data provided in Fig. 4 yields a convenient design guideline for achieving minimum modulator separation and therefore maximum integration density. To avoid possible performance degradation of a transmitter PIC in this generic foundry, modulator separation should exceed $50 \mu \mathrm{m}$ and ground return paths should be isolated from each other.

\section{CONCLUSION}

We have designed and fabricated four different types of modulator test structures and characterized their electrical coupling. A shared ground return path has been identified to generate a large amount of crosstalk. In absence of this common ground return, coupling decreases with increasing separation distance and a quantitative relation is presented. The electrical crosstalk leads to optical performance degradation of the modulators in form of eye diagram distortions and power penalties in the back-to-back transmission. Finally we have shown a relation between electrical crosstalk and transmission power penalty which yields a 1 $\mathrm{dB}$ tolerance for $-40 \mathrm{~dB}$ crosstalk at $10 \mathrm{~Gb} / \mathrm{s}$ modulation speed. To stay below this level, the separation distance between modulators based on microstrip and stripline electrodes should exceed $50 \mu \mathrm{m}$ in integration platforms based on $\mathrm{n}$-doped substrates.

\section{REFERENCES}

[1] R. Nagarajan et al., "Large-scale photonic integrated circuits," IEEE J. Sel. Topics Quantum Electron., vol. 11, no. 1, pp. 50-65, Feb. 2005.

[2] P. Evans et al., "1.12 Tb/s superchannel coherent PM-QPSK InP transmitter photonic integrated circuit (PIC)," Opt. Express, vol. 19, no. 26, pp. B154-B158, Dec. 2011.

[3] M. Smit et al., "An introduction to InP-based generic integration technology," Semicond. Sci. Technol., vol. 29, no. 8, Jun. 2014, Art. no. 083001.

[4] N. Andriolli et al., "InP monolithically integrated coherent transmitter," Opt. Express, vol. 23, no. 8, pp. 10741-10746, Apr. 2015.

[5] K. Lawniczuk et al., "AWG-DBR-based WDM transmitter fabricated in an InP generic foundry platform," presented at the Optical Fiber Communication Conf. Expo., San Francisco, CA, USA, Mar. 2014, paper Tu3H.2.

[6] S. Stopinski, M. Malinowski, R. Piramidowicz, M. K. Smit, and X. J. M. Leijtens, "Monolithically integrated 8-channel WDM reflective modulator," presented at the Optical Fiber Communication Conf. Expo., Anaheim, CA, USA, Mar. 2013, paper OW4J.7.

[7] K. Lawniczuk et al., "InP-based photonic multiwavelength transmitter with DBR laser array," IEEE Photon. Technol. Lett., vol. 25, no. 4 pp. 352-354, Feb. 2013.

[8] S. Kanazawa et al., "A compact EADFB laser array module for a future 100-Gb/s ethernet transceiver," IEEE J. Sel. Topics Quantum Electron., vol. 17, no. 5, pp. 1191-1197, Sep. 2011.

[9] S. Kanazawa et al., "Ultra-compact $100 \mathrm{GbE}$ transmitter optical subassembly for 40-km SMF transmission," J. Lightw. Technol., vol. 31, no. 4, pp. 602-608, Feb. 2013.

[10] M. Shishikura, T. Ban, R. Mita, Y. Matsuoka, and K. Nakahara, " $1.3 \mu \mathrm{m} 10$ Gbit/s/channel parallel transmitter and receiver modules," IEIEC Trans. C, vol. J90-C, no. 11, pp. 757-766, 2007, Art. no. IW3A.3.

[11] W. Yao, G. Gilardi, M. Smit, and M. J. Wale, "Performance degradation of integrated modulator arrays due to electrical crosstalk," presented at the Integrated Photonics Research, Silicon Nanophotonics, San Diego, CA, USA, Jul. 2014, paper IW3A.3.

[12] W. Yao, G. Gilardi, N. Calabretta, M. K. Smit, and M. J. Wale, "Experimental and numerical study of electrical crosstalk in photonic integrated circuits," J. Lightw. Technol., vol. 33, no. 4, pp. 934-942, Feb. 2015.

[13] W. Yao, G. Gilardi, M. Smit, and M. Wale, "Electrical crosstalk in integrated Mach-Zehnder modulators caused by a shared ground path," presented at the Integrated Photonics Research, Silicon Nano Photonics, Boston, MA, USA, 2015, paper IM2B.3.

[14] G. L. Li et al., "High-saturation high-speed traveling-wave InGaAsPInP electroabsorption modulator," IEEE Photon. Technol. Lett., vol. 13, no. 10, pp. 1076-1078, Oct. 2001.

[15] E. Goldstein, L. Eskildsen, and A. Elrefaie, "Performance implications of component crosstalk in transparent lightwave networks," IEEE Photon. Technol. Lett., vol. 6, no. 5, pp. 657-660, May 1994.

[16] I. Monroy, E. Tangdiongga, and H. de Waardt, "On the distribution and performance implications of filtered interferometric crosstalk in optical WDM networks," J. Lightw. Technol., vol. 17, no. 6, pp. 989-997, Jun. 1999.

Weiming Yao (S'16) was born in Zhangjiakou, China, in 1987. He received the B.Sc. degree in electrical engineering from Technische Universität Berlin, Berlin, Germany, in 2010, and the two M.Sc. degrees in photonic networks engineering as a part of an Erasmus Mundus program from Aston University, Birmingham, U.K., Scuola Superiore Sant'Anna Pisa, Pisa, Italy, and Osaka University, Osaka, Japan, in 2012. Since November 2012, he has been working toward the Ph.D. degree at the Photonic Integration Group, Eindhoven University of Technology, Eindhoven, the Netherlands, where his work focuses on the design and characterization of high bandwidth integrated multichannel transmitter PICs.

Giovanni Gilardi received the master's and Ph.D. degrees in electronic engineering from the University of Rome Sapienza, Rome, Italy, in 2011. He joined the Institute for Microelectronics and Microsystems of the Italian National Research Council, Rome, in 2008. From 2012 to 2015, he was a Postdoctoral Researcher at Photonic Integration Group, Eindhoven University of Technology where he had been working on design, fabrication, and characterization of integrated transceivers based on InP. Now, he is with the Infinera Corporation. His Ph.D. thesis has been recently awarded by the Italian Liquid Crystal Society. 
Meint K. Smit (F'03) received the Graduation degree in electrical engineering in 1974 and the Ph.D. degree in 1991 from the Delft University of Technology, Delft, the Netherlands, both with honours. He started research in Integrated Optics in 1981. He invented the Arrayed Waveguide Grating, for which he received an LEOS Technical Achievement Award in 1997 and he was closely involved in the introduction of MMI-couplers in semiconductor-based Photonic IC technology. Until 2014, he was the Leader of the Photonic Integration Group at the COBRA Research Institute of TU Eindhoven. His current research interests include InP-based Photonic Integration, including integration of InP circuitry on silicon. He is an IEEE Photonics Society Fellow. In 2012, he received an ERC Advanced Grant, and in 2016 he received the Rank Prize for the invention of the Arrayed Waveguide Grating.
Michael J. Wale (M'92) received the B.A., M.A., and D.Phil. degrees in physics from the University of Oxford, Oxford, U.K. He is the Director of Active Products Research at Oclaro, based at Caswell, U.K. Since moving into industry in the early 1980s, he has been involved in many different aspects of research, development, and manufacturing of photonic devices and systems, with particular emphasis on photonic integrated circuit technology. Alongside his role at Oclaro, where he has responsibility for strategic technology activities, he is a Professor of Photonic Integration/Industrial Aspects at the Eindhoven University of Technology, Eindhoven, the Netherlands, and an Honorary Professor at the University of Nottingham, Nottingham, U.K. He is a member of the Executive Board of the European Technology Platform, Photonics21, and the Chairman of its Working Group on Design and Manufacturing of Optical Components and Systems. He is a member of the Optical Society of America and is the author/coauthor of approximately 200 publications. 